\title{
Editorial
}

\section{Reviewer recognition and editor's note 2019}

https://doi.org/10.1515/aot-2019-0006

2019 will be a year of change. According to recent forecasts [1] the growth in photonics markets will cool down to a few percent, which comes after some exciting years such as 2017 with strong $21.6 \%$ growth. After an unusually long economic upswing we see business calming.

Analysts name some reasons such as new tariffs, and Brexit. Whether it is coming or not, Brexit will have a longlasting influence on Europe. Today's academic research is based on international collaboration, so any separating efforts are disastrous. Some UK scientists have already established strategic alliances with their continental colleagues to soften the effects of Brexit on their funding situation [2].

Fortunately, academic publishing is widely independent of such trends. We have the inspiring task to track and to mirror new technological trends. This we did in 2018 and so we plan for 2019. Currently, we have four topical issues confirmed for this year:

- Illumination optics (Guest editors: Cornelius Neumann, Tran Quoc Khanh)

- Interdisciplinary simulation (Guest editors: Alois Herkommer, Fabian Duerr)

- 3D lithography (Guest Editors: Robert Kirchner, Jun Taniguchi)

- Microscope objectives
The latter refers to a unique project where Yueqian Zhang and Herbert Gross from the Friedrich Schiller University Jena embark on giving a systematic review of the optical design of microscope objectives across all major manufacturers. It is quite unusual to reserve one issue for one team of authors, but in this case it appears well legitimated by the size of the material and the reputation of the authors.

\section{Annual citation statistics}

Reputation is an important topic. Advanced Optical Technologies (AOT) has increased its impact in 2018. Elsevier's CiteScore for AOT has again increased, now it stands at 1.31, meaning that on average, every three AOT papers are cited 4 times. This is a nice improvement after 0.69 (2015) and 0.99 (2016). The forecast for 2018 is already positive: as of the 7th of January we stand at 1.33 which may increase in the next months as more documents from 2018 are scanned. This places AOT among reputed titles such as Applied Optics (1.84), and Optical Engineering (1.12).

\section{Reviewers in Advanced Optical Technologies}

Any progress in AOT's reputation is based on quality. While this sounds simple, in reality it is not. Every manuscript that is not immediately rejected goes through a careful peer review process. At least two peers read and comment on the manuscript. These comments usually help to improve the quality of the manuscript.

Thus, we see every day how fundamental a careful peer review works for the quality of manuscripts and therefore for the quality of the journal. Our readers acknowledge this by increasingly citing the journal. In turn, I would like to take the opportunity to give these

www.degruyter.com/aot

(c) 2019 THOSS Media and De Gruyter reviewers a public acknowledgment. These reviewers have contributed voluntarily to make this ongoing success possible. Thank you very much! In the following you will find all the reviewer names of those who did such a careful job for AOT authors in 2018:

Antonio Ancona

Jan Audenaert

Stefan Bauemer

Jörg Baumgart

Matthias Beier

Peter Bender

Stephan Berlitz

Jörn Bonse 
Ulf Brauneck

Timothy Bunning

Jan Burke

Laurent Calvez

William Cassarly

Xinbin Cheng

Ya Cheng

Oliver Dross

Jörg Eberhardt

Zexin Feng

R. A. S. Ferreira

Lawrence Flynn

Ichiro Fujieda

Roland Geyl

Arnold Gillner

Matthew Greenhouse

Hongyu Guan

Carsten Gut

P. Shiv Halasyamani

Shaul Hanany

Lakshminarayan Hazra

Alois Herkommer

Andrew Hicks

Gary Hill

Alexander Horn

Lei Huang

Heinz Huber

Wolfgang Husinsky

Valery Jacobs

Peter Jäschke

David Jenkins

Marco Jupe

Malgosia Kaczmarek

I.C. Khoo

Sang-Jae Kim

Adam Klej

Bob Kruizinga

Jeff Kuhn

Roland Lachmayer

Grigory Lazarev

Qingyu Meng

Akihiro Mochizuki

Cornelius Neumann

Hiroyuki Niino

James Oliver
Heidi Ottevaere

Samuel Pellicori

Mikhail E. Povarnitsyn

Francesco Prudenzano

Gediminas Raciukaitis

Victor Reshetnyak

Kathleen A. Richardson

Francois Riguet

Detlev Ristau

Bernhard Roth

Giacomo Salvadori

Shannon Sankar

Marc Schnieper

Henning Schröder

Georgiy Shakhgildyan

Frank Siegel

Harun H. Solak

Steffen Sommer

Johannes Stock

Slawomir Sujecki

Oliver Suttmann

Matteo Taccola

Juha Toivonen

Klaus Trampert

Giorgios Tsibidis

Michael Vergöhl

SteffenWeissmantel

Jianing Yao

Jianing Youngman

Klaus Zimmer

Yours sincerely,

\section{Andreas Thoss}

Publisher

Michael Pfeffer

Editor-in-Chief

\section{References}

[1] 'What goes up...', G. Overton, A. Nogee, D. Belforte, J. Wallace, B. Gefvert, Laser Focus World 55, 40 (2019).

[2] 'Bracing for Brexit', M. Moser, Optics \& Photonics News, 14. December 2018, www.osa-opn.org/home/newsroom/2018/ december/bracing_for_brexit/. 


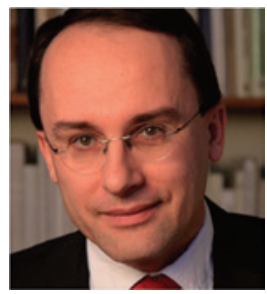

Andreas Thoss studied physics and received the diploma and PhD degrees from the Free University Berlin in 1995 and 2003, respectively. For both degrees, he did research at the Max-Born-Institute Berlin on the field of ultra-short and ultra-intense laser pulses. From 1996 to 1999, he worked as a development engineer for medical laser systems with Aesculap-Meditec (now ZEISS Meditec) in Jena. In 2003 he joined the international publishing house John Wiley \& Sons. There, he gathered comprehensive experience as publisher, editor and commissioning editor in the areas of book, journal and online publishing. Among others, he co-founded the journals Laser \& Photonics Reviews (2007) and the Journal of Biophotonics (2008). Since its foundation in 2010 he manages THOSS Media, where he co-founded Advanced Optical Technologies.

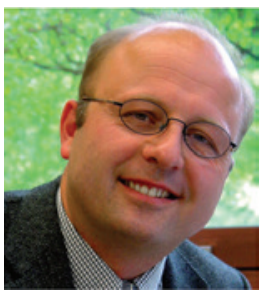

Michael Pfeffer graduated in 1998 at the Institute of Applied Optics at EPFL (Switzerland), obtaining his PhD for a thesis in the field of Optical Nanotechnology. In 2002, after several years working in the Swiss optics industry, he was appointed Full Professor of Optics and Engineering in the Department of Physical Engineering of Hochschule Ravensburg-Weingarten, University of Applied Sciences (Germany). Dr. Pfeffer teaches and researches in the field of optics, physical instrument design and nanotechnology. Currently, he serves as Vice-Rector for Research and International Relations. In 2005, the General Membership Meeting elected him to the Executive Board and CEO for the DGaO-Annual Meeting 2006. From 2008 to 2012 he served as President of the German Society of applied Optics (DGaO). In 2012 he was elected as Secretary of the Board of the European Optical Society (EOS). Dr. Pfeffer is member of the German Physical Society (DPG), the German Society of Engineers (VDI), and the Standards Committee Precision Engineering and Optics of the German Institute of Standardisation (DIN). 